\title{
6
}

\section{OPRESSÃO E VIOLÊNCIA EM POEMAS DE ARMANDO FREITAS FILHO}

OPRESSION AND VIOLENCE IN POEMS BY ARMANDO FREITAS FILHO

\author{
Davi Lemos Reis 1 \\ Universidade de Franca \\ Vera Lucia Rodella Abriata ${ }^{2}$ \\ Universidade de Franca
}

Resumo: Com base no instrumental teórico da semiótica francesa, este artigo analisa três poemas de Armando Freitas Filho, constituintes de um tríptico que foi publicado na obra Raro mar (2006). Objetiva-se apreender o percurso do sujeito do enunciado e o modo como o enunciador constrói o percurso temático-figurativo da violência social, que é internalizada por esse sujeito, e que ele exterioriza em atos que destroem a si mesmo e ao outro. Analisam-se os valores inscritos nos três poemas não somente a partir de sua organização linguístico-discursiva, mas também pelo exame das relações intertextuais que neles se manifestam.

Palavras-Chave: Semiótica francesa; Figura; Tema; Intertextualidade; Armando Freitas Filho.

\footnotetext{
Endereço eletrônico: davilemosreis1@gmail.com.

2 Endereço eletrônico: vl-abriata@uol.com.br.
} 
Abstract: Based on the theoretical instrumental of French semiotics, this paper analyzes three poems by Armando Freitas Filho, constituents of a triptych that was published in the work Raro mar (2006). The objective is to aprehend the enunciate subject's path and the way in which the enunciator creates the thematic-figurative process of social violence which is internalized by this subject and that he externalizes in acts that destroy himself and the other. The values inscribed in the three poems are analyzed based not only on their linguistic-discursive organization but also on the examination of the intertextual relations that are manifested in them.

Keywords: French semiotics; Figure; Theme; Intertextuality; Armando Freitas Filho.

\section{INTRODUÇÃO}

A poesia reconhece-se por esta propriedade: ela tende a se fazer reproduzir em sua forma, ela nos excita a reconstituí-la identicamente.

Paul Valéry

O poeta francês Paul Valéry (1991, p. 205), em Poesia e pensamento abstrato, refletindo sobre o efeito da poesia na vida humana, tece a seguinte consideração: "Penso sinceramente que se todos os homens não pudessem viver uma quantidade de outras vidas além da sua, eles não poderiam viver a sua". A poesia, como forma literária de caráter estético, possibilita ao leitor experenciar outras vidas a partir da palavra poética, vislumbrando na construção de uma subjetividade individual o sentimento do mundo, como revela Carlos Drummond de Andrade (1977) não apenas em sua obra, assim intitulada, mas também, particularmente, em versos de Canção amiga que faz parte de sua primeira obra poética, de 1930, Alguma poesia: “Caminho por uma rua/que passa em muitos países".

É o que se observa em poemas de Raro mar, do poeta Armando Freitas Filho (2006), coletânea na qual a figura raro mar não se circunscreve ao espaço carioca, uma vez que o enunciador ${ }^{3}$ parte da dimensão local e atinge a

3 Para Greimas e Courtés (2011, p. 171), a estrutura enunciativa, pressuposta pela existência do enunciado, é composta de duas instâncias: a do enunciador e a do enunciatário. O primeiro é o "destinador implícito da enunciação" e o segundo, o destinatário, que é considerado também um 
universalidade devido ao valor estético da obra, que suscita no enunciatário o efeito de sentido de verdade, sensibilizando-o para aspectos da dimensão social apreensíveis nos textos.

Nessa obra do poeta carioca (FREITAS FILHO, 2006), encontra-se um tríptico constituído dos poemas $O$ arquiteto, O homem bomba e Ecce homo, os quais são objeto de análise deste artigo. Nosso objetivo é apreender, por meio do referencial teórico da semiótica francesa, a organização temático-figurativa dos textos, voltando-nos particularmente para o percurso do sujeito do enunciado, projetado num espaço urbano violento e opressor.

Convém lembrar aqui que a semiótica francesa entende a produção dos sentidos do texto como um percurso gerativo que vai do mais simples e abstrato ao mais complexo e concreto num processo de enriquecimento semântico (FIORIN, 2008). É importante ressaltar, nessa perspectiva, a diferença que se estabelece entre texto e discurso para a semiótica. Ambos são produzidos no ato enunciativo; mas enquanto o discurso é da ordem da imanência, o texto é do domínio da realização (FIORIN, 2012). As estruturas discursivas manifestam-se, por sua vez, como texto, ao se unirem a um plano de expressão (FIORIN, 2008). O discurso, sendo, portanto, da ordem da estrutura e do acontecimento, faz parte do patamar de superfície do texto, ou seja, do nível discursivo do percurso gerativo, o mais próximo da manifestação textual. É no nível das estruturas discursivas que o enunciador projeta figuras de atores, de espaço e de tempo como simulacros icônicos do mundo sensível, com base numa espécie de representação mimética de um lado e, de outro, num processo gradual, afastando-se dela por meio da abstração (BERTRAND, 2003).

Vale mencionar aqui a distinção entre os procedimentos de figurativização e tematização. Pertencentes ao nível da semântica discursiva do percurso

\footnotetext{
"sujeito produtor do discurso", pois a leitura é considerada, em semiótica, um "ato de linguagem (um ato de significar)", como a própria produção do discurso. Vale lembrar que o termo "sujeito da enunciação" recobre os papéis actanciais do enunciador e do enunciatário.
} 
gerativo de sentido, a tematização é o processo por meio do qual o enunciador dota "uma sequência de figuras de significações mais abstratas que têm por função alicerçar os seus elementos e uni-los, indicar sua orientação e finalidade, ou inseri-los num campo de valores cognitivos ou passionais" (BERTRAND, 2003, p. 213).

Para Greimas (2002, p. 74), a figuratividade é "essa tela do parecer cuja virtude consiste em entreabrir, em deixar entrever, graças ou por causa de sua imperfeição, como que uma possibilidade do além (do) sentido". Segundo Bertrand (2003, p. 405), a figuratividade pode ser representada como a "antecena do sentido", a "fachada mais concreta do discurso", quando, ao contrário do discurso abstrato e de suas formas de racionalidade, surgem na língua as imagens da experiência sensível do mundo. Assim, ultrapassando a definição estrutural de figuratividade, que supunha um vínculo de "representação unívoca entre a palavra e o mundo", deve-se entender, de acordo com o semioticista francês, que a correspondência entre essas duas instâncias se faz por meio do crivo cultural, que torna possível a legibilidade figurativa.

Figuras e temas são, por outro lado, o lugar da inserção dos valores sóciohistóricos e ideológicos nos textos. Conforme Barros (2009, p. 353), a exterioridade, da perspectiva semiótica, pode ser observada pela análise da organização linguístico-discursiva dos textos, especialmente dos percursos temático-figurativos neles inscritos, os quais desnudam suas "determinações histórico-sociais inconscientes". Outro caminho de inserção da exterioridade nos textos pode se dar pela observação das relações intertextuais e interdiscursivas que os textos e os discursos mantêm com aqueles com os quais dialogam.

Vale lembrar, nesse aspecto, a diferença que se estabelece entre intertextualidade e interdiscursividade. Para Fiorin (1994, p. 30-32), “a intertextualidade é o processo de incorporação de um texto em outro, seja para reproduzir o sentido incorporado, seja para transformá-lo". Por sua vez, “a 
interdiscursividade é o processo em que se incorporam percursos temáticos e/ou percursos figurativos, temas e/ou figuras de um discurso em outro".

Os outros dois níveis do percurso gerativo de sentido, o nível narrativo e o nível fundamental, são aqueles nos quais a invariância e a abstração vão se estabelecendo. $\mathrm{O}$ nível narrativo simula a história de um sujeito em busca de valores, investidos em objetos, que dão sentido a sua existência (BARROS, 1988). Sujeito é um papel actancial que, no nível discursivo, pode ser concretizado por um ator figurativizado como João, por exemplo. Os papéis actanciais são, pois, invariantes. Nesse nível, os sujeitos simulam o fazer do homem que transforma o mundo. Assim, narratividade, em semiótica, tem dois sentidos que se complementam. Um deles se relaciona à transformação de estados de um sujeito e o outro diz respeito ao estabelecimento ou à ruptura de contrato entre um Destinador e um destinatário. Nesse aspecto, nenhum sujeito age, visando à conquista de seu objeto de valor, se não estiver dotado de determinada competência para tal fazer, que lhe é outorgada por um Destinador. (BARROS, 1988). Essa competência se dá por meio da aquisição de objetos modais: o querer, o dever, o saber e o poder-fazer. Desse modo, dotado de competência, o sujeito pode transformar seu estado, tornando-se conjunto com determinado objeto de valor. Contudo, se sua competência for enganosa, ele que poderia estar conjunto com determinado objeto de valor pode perdê-lo, tornando-se disjunto de seu objeto. A partir de seu fazer, o sujeito, ao final de seu percurso, é sancionado positiva ou negativamente por um Destinador. Desse modo, sujeito do fazer, sujeito de estado, objeto de valor, Destinador-manipulador, Destinador-julgador são papéis actanciais invariantes do nível narrativo que se manifestam como figuras variáveis no nível discursivo.

Enfim, o nível fundamental do percurso gerativo de sentido, o mais simples e abstrato, é aquele em que se apreendem as categorias semânticas que estão na base de construção de um texto (FIORIN, 2014). Tais categorias estão 
fundamentadas numa oposição de sentido cujos termos são qualificados como eufóricos ou disfóricos. Euforia e disforia estão inscritas no texto e cabe ao enunciatário apreendê-las. Assim, pode haver diferentes estruturas discursivas em que se pode apreender a oposição semântica vida vs. morte. Em um discurso no qual o enunciador projeta um ator suicida, por exemplo, a morte pode ser eufórica e a vida, disfórica. No nível narrativo, esse mesmo ator, enquanto sujeito, pode assumir o papel actancial de um sujeito do fazer que, anteriormente conjunto com o objeto de valor vida, por meio de seu fazer, o suicídio, torna-se dele disjunto. Apresentados de forma sucinta os três níveis do percurso gerativo de sentido, cujos elementos serão utilizados em nossa análise dos poemas de Armando de Freitas Filho, faremos menção ao autor e sua obra, representativa da poética brasileira contemporânea.

Freitas Filho, poeta carioca, é vencedor de diversos prêmios literários, como o Jabuti (1986), pelo livro 3x4, Alphonsus Guimarães (2014), com o livro Lar, da Fundação Biblioteca Nacional. Raro Mar é uma obra de caráter dialógico, especialmente pela alusão à poesia de Drummond com a qual o poeta compartilha a denúncia em relação à violência e à opressão em um claro caminho para a poesia social.

Viviana Bosi (2011, p. 113) observa que a obra de Freitas Filho é marcada pela "negatividade que não desiste nem se dobra" e traz o registro do "sujeito e vida contemporâneos". Esse ponto de vista é compartilhado por Mário Alex Rosa (2009). O pesquisador afirma que, em Raro mar, o poeta, como "dono de seu tempo", traz-nos uma "amostra dos grandes centros do Brasil de hoje, em particular o Rio de Janeiro" (ROSA, 2009, p. 71). Rosa destaca a coexistência de uma mímese na poesia de Armando: “a experiência deflagrada aqui não é apenas o propósito de uma poesia social, política, mas o olhar do sujeito lírico que não se vê indiferente à paisagem ao seu redor" (ROSA, 2009, p. 71). 
A partir desses elementos teóricos, procuraremos analisar o percurso do sujeito que se manifesta nos poemas do tríptico, observando o modo como o enunciador, simulacro do poeta Freitas Filho, projeta-o na figura de um ator anônimo, num espaço-tempo que corporifica a urbe brasileira contemporânea. Nosso intento é, pois, desvelar, por meio da organização temático-figurativa dos textos, as relações intertextuais que neles se apreendem e a forma como o enunciador tematiza a violência e a opressão que se disseminam nesse contexto. Vamos, portanto, à análise do primeiro poema.

A ARQUITETURA DO ASSALTO

\section{$\mathrm{O}$ arquiteto}

Emparedado ou preparado no quarto-forte

no aparelho sem janela, cada dia

à cabeceira, o copo d'água

se envenena, escurece, o relógio

de pulso retroativo, vai em frente

irredutível, bate seco na quadra

do tempo, na superfície da vida.

Sonho preto de labiríntica engenharia

se levanta em linha reta, contra a luz

o sol, ao ar livre, pronto para o assalto.

(FREITAS FILHO, 2006, p. 52)

No primeiro poema do tríptico, o enunciador projeta um narrador observador $^{4}$ que relata o percurso de um sujeito do enunciado, desprovido de um nome que o individualize, sendo identificado pelo papel temático de arquiteto. A projeção espacial desse sujeito se dá em um espaço fechado, manifestado pelas figuras aparelho e quarto-forte. Uma das acepções de aparelho, segundo o dicionário Houaiss (2009), relaciona-se a "local que abriga reuniões de

4 Para Greimas e Courtés (2011, p. 347), o observador "é um sujeito cognitivo, delegado pelo enunciador" que, no discurso enunciado, pode estar em sincretismo com o narrador implícito e exercer o fazer interpretativo sobre outros actantes narrativos. 
grupos políticos clandestinos, serve como esconderijo, guarda de material etc.". Quarto-forte, por sua vez, é um “local especialmente preparado para abrigar loucos furiosos nos hospícios"' (HOUAISS, 2009).

O sujeito inserido nesse ambiente encontra-se emparedado, ou seja, “encerrado entre paredes" (HOUAISS, 2009) e está prestes a realizar um assalto, o que se revela no último verso do poema. O observador sugere que essa ação é insana, sancionando-a negativamente, uma vez que utiliza a figura quarto-forte, como sinônimo de aparelho. Tais figuras remetem ao percurso temático do isolamento do sujeito, que está insulado nesse espaço, preso a uma situação rotineira, o que se evidencia pela circunstância temporal expressa na figura cada dia, alusiva ao copo d'água, como se nota nos versos: “Emparedado ou preparado no quarto-forte / no aparelho sem janela, “cada dia à cabeceira, o copo d'água / se envenena".

O indivíduo, que se encontra cotidianamente enclausurado nesse ambiente, vivencia uma espécie de rotina inescapável. Em estado de clandestinidade, solitário, há, pois, o apagamento da individualidade do sujeito que, inscrito na engrenagem do sistema, revela-se incompetente, - não poder fazer - para romper o contrato estabelecido com um destinador que lhe delegou o dever de ali estar no preparo da ação cotidiana. Ele encontra-se, na verdade, manipulado para realizar um fazer que lhe foi outorgado.

É importante mencionar ainda a escolha da figura envenena, que denomina a ação operada pela água; embora esta seja essencial à vida do ser humano, adquire no contexto uma conotação disfórica. Dessa forma, o observador, ao dotar o copo d'água do poder de se envenenar, sugere que, na rotina violenta do dia a dia, tem o poder de destruir aos poucos o sujeito, impotente para romper com o círculo vicioso do cotidiano opressor no qual se situa. Nota-se, assim, que o observador relata o percurso de um sujeito que se submete à rotina opressora, sendo modalizado por um dever-fazer e por um não-poder-não-fazer. 
Esse sujeito se desvela de forma metonímica pelos objetos que compõem o espaço do quarto-forte, figurativizados pelo copo d'água e pelo relógio: “o relógio, de pulso retroativo / vai em frente / irredutível, bate seco na quadra do tempo, na superfície da vida". Convém destacar a personificação da figura relógio que, embora opere a ação de ir em frente, cronometrando o tempo da vida, retroage. De acordo com o dicionário Houaiss (2009), retroativo pode ser definido como "aquilo que tem efeito ou influi sobre fatos passados". Logo, embora o sujeito siga seu percurso temporal e vai em frente, é, contudo, marcado pelo passado. Pressupõe-se que no pretérito ele realizava as mesmas ações rotineiras e opressivas que mantém no presente, mas segue em frente em seu percurso. Essa rotina é, portanto, uma obrigação à qual o sujeito se submete, assumindo um estilo de vida que se prolonga na quadra do tempo e se estende pela superfície da vida: um estilo de vida a que ele se encontra aprisionado.

É importante ressaltar que, em termos de localização espacial, o texto estabelece uma oposição entre um espaço interno, habitado pelo sujeito, fechado e escuro, o quarto-forte, e um espaço exterior, aberto e luminoso, para onde ele se dirige, utilizando uma máquina possante, como se observa nas figuras presentes nos três últimos versos do poema: "Sonho preto de labiríntica engenharia / se levanta em linha reta, contra a luz / do sol, ao ar livre, pronto para o assalto". Nesse aspecto, observa-se no texto a oposição semântica opressão vs. liberdade, na qual o primeiro termo é disfórico e o segundo, eufórico, como se observará na sequência da análise.

A figura sonho preto de labiríntica engenharia designa, pois, um carro, que irá se concretizar no terceiro poema do tríptico, Ecce Homo. O carro que o sujeito dirige contra a luz do sol é a máquina com a qual ele realizará um assalto. Tal figura, metafórica, revela a ironia do enunciador em relação ao objeto carro que, dotado de um valor mítico, não somente faz parte dos sonhos do sujeito, mas tem o poder de se levantar e operar um assalto por meio de suas mãos, desvelando o 
tema do consumismo que, atrelado ao tema da violência, irá se revelar no segundo poema do tríptico.

O sujeito segue assim um percurso iniciado no quarto-forte, espaço onde arquiteta o assalto que está prestes a realizar. A arquitetura, no sentido de “elaboração de um empreendimento futuro; plano, projeto" (HOUAISS, 2009) é, por conseguinte, em termos metafóricos, a arquitetura de um assalto.

A seguir analisamos o segundo poema do tríptico no qual se dá a sequência do percurso do arquiteto.

\section{O CORPO E A CIDADE EM O HOMEM BOMBA}

O corpo insuportável erra, se auto-empurra

calcificado, intramuros, e no caminho.

Atravessa trincheiras incorporando

o entulho das paredes repetentes

entranhadas em si, indissociáveis, com o que tem

de similar à alvenaria: osso, dente, unha, cálculo

cumprindo o destino mal traçado nas linhas da mão no seu alcance máximo, e purga, na implosão da fé.

(FREITAS FILHO, 2006, p. 52)

Em O homem bomba, o arquiteto, programado para o assalto anunciado no primeiro poema, concretiza-se inicialmente por meio da figura metonímica de um corpo errante a percorrer os espaços da cidade. As figuras erra, se autoempurra, atravessa trincheiras, purga referem-se às ações do sujeito que se sucedem no presente pontual.

Fiorin (1996, p. 149) diz que o presente pontual é aquele no qual o momento de referência coincide com o momento do acontecimento e com o momento da enunciação. Desse modo, o enunciador aproxima-nos, enquanto enunciatários, do corpo do arquiteto que percorre a cidade em seu fazer cotidiano, corpo que o olhar do observador sanciona como insuportável. 
É importante notar que o sujeito se localiza espacialmente entre trincheiras. Segundo o Houaiss (2009), trincheira pode significar "local em que se trava uma batalha, em que se luta". O ambiente em que ele se encontra é, portanto, como sugere essa figura, um ambiente que se associa ao tema da violência, da guerra urbana tão presente no cotidiano das grandes cidades.

O corpo do sujeito se manifesta por meio de fragmentos, como se nota pela presença de outras figuras metonímicas (osso, dente, unha), que são indissociáveis das paredes entranhadas em si. Revela-se, pois, no texto, um percurso figurativo em que se fundem os fragmentos do sujeito a elementos do espaço que percorre. Nessa perspectiva, as figuras paredes entranhadas em si, corpo calcificado remetem ao tema da indissociação entre fragmentos do espaço e do sujeito errante.

O percurso constituído das figuras intramuros, entulho das paredes repetentes remete, assim, a elementos de um espaço que está em processo de destruição por um conflito, marcado pela presença das trincheiras. Essa destruição é fruto do fazer do indivíduo que, por meio dele, torna-se também um estilhaço amalgamado aos despojos da cidade que a ele se incorpora. O sujeito, metonimizado por um corpo fragmentado, opera, pois, um trabalho brutal, exercendo o papel temático de um homem-bomba, que atravessa trincheiras. Nesse sentido, entende-se a razão de o sujeito ser identificado por seus papéis temáticos: o enunciador tematiza, desse modo, o apagamento da própria individualidade do sujeito que é meramente um corpo fragmentado a errar pela cidade semeando violência e destruição.

Nota-se também, no poema, o tema da reificação do humano no sincretismo, na fusão que se estabelece entre fragmentos do corpo do sujeito e objetos da paisagem urbana que concomitantemente implodem junto com ele. É dessa forma que o enunciador alude ao tema da violência que grassa nas grandes cidades em nosso contexto atual. Vale ressaltar que a figura entulho das paredes repetentes entranhadas em si remete não somente ao tema do sincretismo entre o 
humano e os entulhos da cidade, mas também indicia o fazer interpretativo do observador sobre o sujeito, o homem-bomba: um sujeito cujo estilo de vida espelha a violência do espaço urbano do Brasil contemporâneo.

Logo, a arquitetura do assalto, no primeiro poema, revela um sujeito virtual, sujeito de um dever-fazer, que se torna um sujeito realizado neste segundo poema, na medida em que transforma estados ao longo de seu percurso como sujeito do fazer: um fazer destruidor, violento sobre a cidade, fazer que ao mesmo tempo o autodestrói.

A figura trincheiras é, por sua vez, metafórica e alude ao tema da violência que toma conta do espaço que o sujeito percorre cotidianamente. Por outro lado, a figura purga na explosão da fé é ambígua, pluri-isotópica. Refere-se tanto à implosão do espaço que o sujeito destrói na explosão, autodestruindo-se ao mesmo tempo, quanto à possibilidade de se purgar, de se libertar da situação opressiva, insuportável em que se encontra, por meio da crença numa saída transcendental. Assim, nota-se um outro percurso figurativo no texto que reúne as figuras destino, purga, fé. Destino, segundo o Houaiss (2009), significa “tudo que é determinado pela providência ou pelas leis naturais, sorte, fado, fortuna". Vale destacar que o destino é caracterizado pelo observador como mal traçado nas linhas da mão do sujeito e se relaciona a um porvir sobrenatural, uma ordenação transcendental que a ele estaria destinada.

Essa leitura remete a um sujeito que não é dono do próprio destino, ele cumpre um contrato a ele imposto por um destinador que lhe delegou um deverfazer, o dever de continuar a ser um participante da rotina violenta do espaço que habita. Desse modo, o observador, ao caracterizar tal destino como mal traçado nas linhas da mão do sujeito, ironicamente remete-nos a um fado trágico, disfórico, do qual ele não poderia fugir. Purgar, por outro lado, significa "tornar puro, livrar-se de impurezas, depurar, purificar, limpar; remir culpa, expiar pecados, pagar, redimir-se" (HOUAISS, 2009). Relaciona-se, portanto, enquanto 
figura do discurso, ao tema religioso da expiação dos pecados que leva o sujeito a se redimir por meio do suicídio. Logo, como homem bomba que é, liberta-se ironicamente de um destino opressivo e trágico, através da implosão que lhe causa a morte, operada por ele como um ato violento de destruição de si e do outro, ambos indeterminados, já que sujeito e espaço não são nomeados no texto.

Observa-se, portanto, no texto a oposição semântica do nível fundamental opressão vs. liberdade, na medida em que observador sugere que a única via de esse sujeito libertar-se da violência é por meio da crença numa saída transcendental, que alcançaria com o suicídio, por meio do qual ele se torna disjunto do objeto de valor vida.

Desvela-se assim a visão negativista do observador sobre a violência que grassa no cotidiano da urbe contemporânea.

\section{ECCE HOMO: A PROJEÇÃO DO CONTEXTO NO TEXTO}

Ecce homo, o último poema do tríptico, objeto desta análise, traz no título a expressão latina que equivale a Eis o homem.

\section{Ecce homo}

Asfalto pânico. A flor não fura mais

a dura casca preta. O terno, depois

o carro blindado até os dentes do radiador.

Colete à prova de bala, roda de titânio

Que o terror sem rosto dirige, explosivo

Invisível, atrás de vidros negros -

Fúnebre e fantasma - cheiro de couro

Virgem, carne de caralho, loção

Pós-guerra punho, pulso no volante

Segurando não sei quanto cavalos.

(FREITAS FILHO, 2006, p. 53) 
Nesse poema, o enunciador mantém a projeção do observador no tempo presente, constante nos três poemas do tríptico, aproximando-nos, como enunciatários, do espaço e do tempo em que se situa o sujeito do enunciado, com vistas a sensibilizar o enunciatário-leitor sobre a temática da violência. Desse modo, as figuras carro blindado, colete à prova de balas remetem ao tema da violência urbana, materializada nas ruas das grandes cidades.

A alusão à urbe se revela por meio da figura asfalto pânico que pode ser considerada um conector de isotopias, pois asfalto é uma figura metonímica, relacionada não só à pavimentação urbana, mas relacionada ao estado de alma de pânico do sujeito que vivencia o cotidiano das grandes cidades. Observa-se, por conseguinte, no texto, a paixão do medo, que é regida pelo não querer-ser do sujeito, segundo Fontanille (2005, p. 2015). De acordo com o semioticista francês, paixões como o medo, o pavor e o terror implicam uma repulsa em relação ao outro, que pode ser um outro sujeito ou um objeto do mundo.

Nesse sentido, o percurso figurativo apreensível no poema faz menção ao tema da violência, que provoca o pânico no sujeito inserido no espaço contemporâneo e com ele desencantado: ele não queria estar ali, mas ali deve estar e sua única saída é a libertação da opressão por meio do suicídio e da crença, da fé na transcendência.

O tema da violência se concretiza, pois, na rotina aterrorizante, vivenciada pelo sujeito sem rosto, invisível, que se veste com um terno e colete à prova de balas, dirige-se a um carro blindado com roda de titânio e vidros negros, para realizar seu fazer. A figura roda de titânio é constituinte do carro que, por sua vez, é dirigido pelo terror sem rosto. Tal figura é metonímica, na medida em que terror é efeito da violência que o sujeito sofre e, ao mesmo tempo, opera, ao dirigir o carro. Ele também se revela explosivo, invisível, fúnebre e fantasma, segundo outro ponto de vista do observador. 
O terror, personificado, invisível, provoca a morte, metaforizada nas figuras fúnebre e fantasma. Essa personificação remete ao estado de alma de pânico do sujeito que, sem rosto, invisível, vive um cotidiano violento, insuportável.

É importante ressaltar a grande presença de figuras metonímicas, associadas a objetos no texto: carro blindado, com vidros negros, com rodas de titânio, com cheiro de couro, loção pós-guerra. Há ainda a presença de figuras metonímicas relativas a partes do corpo do sujeito: punho, pulso no volante. Inter-relacionados, os dois percursos figurativos remetem ao tema da valorização de objetos e à fragmentação do sujeito, desprovido de individualidade, na sociedade contemporânea. Em nome da conquista de objetos de valor do universo do consumo, frutos da sociedade capitalista, que são qualificados de forma eufórica, com os quais ele sonha, como o carro e a loção utilizada após a guerra cotidiana, o sujeito se desumaniza.

Convém observar ainda o diálogo intertextual que o enunciador, simulacro do autor Freitas Filho, estabelece com o poema A flor e a náusea, de Carlos Drummond de Andrade (1977). Esse diálogo com o texto drummondiano se torna perceptível por meio da menção à flor, figura sobre a qual o observador tece um ponto de vista desesperançado entre o segundo e o terceiro versos do poema: "A flor não fura mais a dura casca preta".

Nesse aspecto, vale lembrar as figuras presentes na primeira parte do poema de Drummond: rua cinzenta; tempo de fezes; mercadorias; crimes da terra; asfalto; bondes; ônibus; rio de aço do tráfego. Elas remetem ao tema da vida urbana, desumanizada no contexto da sociedade de mercado que se implantava no Brasil nos anos 1940, quando foram escritos os poemas de A rosa do povo (1977), coletânea da qual faz parte A flor e a náusea. Os estados de alma do enunciador drummondiano, na primeira parte do poema, são de melancolia, tristeza, revolta, desesperança perante o momento vivido. Já na segunda parte do texto, a flor é figura que, ao nascer nesse ambiente inóspito, é dotada de um papel 
performativo: furar o asfalto, o tédio, o nojo, o ódio. Dessa forma, o enunciador drummondiano revela estados de alma de esperança, relacionados ao nascimento da flor, que tematiza a reconstrução de um mundo sem ódio, sem guerra, contrário ao cenário de desesperança da primeira parte do poema.

Em Ecce homo, por outro lado, o diálogo que o enunciador estabelece com A flor e a náusea é polêmico, uma vez que o sentido da figura flor aqui se opõe ao sentido que ela adquire no poema drummondiano. No texto em tela, a flor não tem mais o poder de brotar e destruir a opressão e a violência, dominantes no espaço-tempo do sujeito do enunciado, um sujeito que, imerso num espaçotempo violento, também se desumaniza, torna-se violento e, ao mesmo tempo, é tomado pelo medo da violência a qual gera e que também o destrói.

É, portanto, dessa forma, que os textos do tríptico se reportam ao contexto brasileiro contemporâneo. $\mathrm{O}$ enunciador, por meio da perspectiva do observador, constrói um ser humano que, fragmentado, valoriza objetos do universo do consumo, como o carro, um sonho preto de labiríntica engenharia, com roda de titânio. O carro que ele dirige aterrorizado, ícone do universo do consumo, é o motor por meio do qual ele opera a destruição e a violência na cidade em que erra, figurativizada metonimicamente pelo asfalto pânico. É a esse espaço metonímico violento e presentificado, metáfora da urbe brasileira contemporânea que, no nível da enunciação, o observador lança seu olhar irônico e negativista.

Em Ecce homo observa-se também um outro diálogo intertextual que o enunciador estabelece com o texto bíblico, ao fazer menção, no título do poema, à fala de Pôncio Pilatos sobre Jesus Cristo no episódio da Paixão. Ecce homo: Eis o homem (BÍBLIA, Jó, 19, 5) teria proferido Pilatos, em tom solene, dotado de um certo desdém, para se referir à figura da cristandade diante de uma multidão de judeus que o acusavam. No contexto do poema de Freitas Filho, observa-se a 
ironia do observador ao citar o enunciado do texto bíblico no qual Cristo é julgado e crucificado.

O tema da crucificação, no poema em análise, alude, de forma metafórica, à crucificação do humano, que é reificado e sucumbe no seio de uma sociedade mercantil em que o objeto de consumo passa a ser glorificado e em nome do qual se gera a violência e a desigualdade social. Assim, o sujeito inscrito no enunciado do tríptico, tomado pelo pânico que atinge as raias do insuportável, mune-se de armas, pronto para o combate ao outro numa sociedade desigual onde seu corpo erra e, em nome do capital e do consumo, gera a violência social e se autodestrói.

\section{CONSIDERAÇÕES FINAIS}

No tríptico de Freitas Filho, o enunciatário, por meio do ato de leitura, é levado a reconstruir o percurso de um sujeito do enunciado não individualizado, que é identificado por seus papéis temáticos: é o arquiteto de um assalto que, como homem bomba, também se autodestrói ao destruir o outro. Por meio do percurso do sujeito do enunciado, o observador desvela assim seu pessimismo em relação à urbe brasileira contemporânea, reconstruída esteticamente como um espaço violento no qual a própria poesia, metaforizada pela flor, vai perdendo terreno. Em A flor e a náusea, de Drummond, o papel performativo operado pela flor, enquanto figura, metáfora da poesia, teria a função de humanização e sensibilização, da perspectiva do enunciador, inserido no contexto dos anos 1940, remetendo ao tema da esperança na reconstrução do mundo pós-guerra e pós ditadura Vargas.

No caso do tríptico de Freitas Filho, a figura flor, no último poema, remete, de forma disfórica, ao tema do desencantamento do observador com o contexto presente em que se situa, estabelecendo assim uma relação polêmica com o texto 
drummondiano, ao observar que a poesia não tem mais o poder de sensibilizar o ser humano, em tempos tão cruéis, marcados pela violência.

Essa seria a forma de o enunciador denunciar o contexto brasileiro contemporâneo por meio dos poemas que compõem o tríptico. Desse modo, visa a estabelecer um contrato de fidúcia com o enunciatário, com o objetivo de leválo a conscientizar-se sobre a tragédia do cotidiano opressor e violento presentificado no tríptico.

Nesse sentido é que, de acordo com Leyla Perrone-Moisés (1990, p. 108), a literatura adquire uma função revolucionária; isso ocorre não por "emitir mensagens revolucionárias", mas pelo poder de levantar "por suas reordenações e invenções, uma dúvida radical sobre a fatalidade do real, sobre o determinismo da história". São essas reordenações e reinvenções que intentamos desvelar na estrutura interna dos poemas de Freitas Filho, especialmente por meio de seus percursos temático-figurativos e pelas relações intertextuais que o enunciador estabelece com o poema $A$ flor e a náusea, de Carlos Drummond de Andrade, e com o texto bíblico.

\section{REFERÊNCIAS}

ANDRADE, Carlos Drummond de. Poesia completa e prosa. Rio de Janeiro: Nova Aguilar, 1977.

BARROS, Diana Luz Pessoa de. Teoria do discurso. Fundamentos semióticos. $1^{\underline{a}}$ ed. São Paulo: Atual, 1988.

BARROS, Diana Luz Pessoa de. Uma reflexão semiótica sobre a "exterioridade" discursiva. Alfa: Revista de Linguística. São Paulo, v. 53, n. 2, p. 351-364, 2009.

BERTRAND, Denis. Caminhos da semiótica literária. Trad. do Grupo CASA. Bauru: Edusc, 2003.

Bíblia Sagrada, Ed. Difusora Bíblica, Coimbra, 2003.

BOSI, Viviana. Poesia em risco (Itinerários a partir dos anos 60). 2011. 327f. (Tese de Livredocência em Linguística). Faculdade de Filosofia, Letras e Ciências Humanas, Universidade de São Paulo, São Paulo. 
FIORIN, José Luiz. Da necessidade da distinção entre texto e discurso. In: BRAIT, Beth; SOUZA-e-SILVA, Maria Cecília (Orgs.). Texto ou discurso? São Paulo: Contexto, 2012.

FIORIN, JOSÉ Luiz. Polifonia Textual e Discursiva. In: BARROS, Diana Luz Pessoa de; FIORIN, José Luiz (Orgs.). Dialogismo, Polifonia, Intertextualidade: Em torno de Mikhail Bakhtin. São Paulo: Ed. da Universidade de São Paulo, 1994.

FIORIN, José Luiz. As astúcias da enunciação. As categorias de pessoa, espaço e tempo. São Paulo: Ática, 1996.

FIORIN, José Luiz. Em busca do sentido. Estudos discursivos. 1aㅡ ed. São Paulo: Contexto, 2008.

FIORIN, José Luiz. Elementos de análise do discurso. 15ª ed. São Paulo: Contexto, 2014.

FONTANILLE, Jacques. "La peur, la crainte, la frayeur, la terreur". In: DITCHE, Elisabeth Rallo; FONTANILLE, Jacques; LOMBARDO, Patrizia. Dictionnaire des passions littéraires. Paris: Belin, 2005.

FREITAS FILHO, Armando. Raro mar. São Paulo: Companhia das Letras, 2006.

GREIMAS, Algirdas Julien; COURTÉS, Joseph. Dicionário de semiótica. $2^{\underline{a}}$ ed. São Paulo: Contexto, 2011.

GREIMAS, Algirdas Julien. Da imperfeição. São Paulo: Hacker editores, 2002.

HOUAISS. Dicionário eletrônico Houaiss da língua portuguesa. Rio de Janeiro: Objetiva, 2009.

PERRONE-MOISÉS, Leyla. A criação do texto literário. In: Flores da escrivaninha. Ensaios. São Paulo: Companhia das Letras, 1990.

ROSA, Mario Alex. Dualidades na poesia de Armando Freitas Filho. 2009. 125f. (Tese de Doutorado - Departamento de Letras Clássicas e Vernáculas). Faculdade de Filosofia, Letras e Ciências Humanas. USP. São Paulo.

VALÉRY, Paul. Poesia e pensamento abstrato. In: Variedades. Trad. de Maiza Martins de Siqueira. São Paulo: Iluminuras, 1991.

Nota do editor:

Artigo submetido para avaliação em: 01 de outubro de 2020.

Aprovado em sistema duplo cego em: 09 de março de 2021. 